\title{
Management of Dystocia in Sheep - A Case Report
}

\author{
A.K. Pandey, Mir Mudasir*, Jaan Mohammad Wani, Sharad Kumar and \\ Sudhir Kumar
}

Division of Veterinary Gynaecology and Obstetrics, FVSc \&AH, R.S Pura, SKUAST-Jammu-181102, India

*Corresponding author

\section{A B S T R A C T}

\section{Keywords}

Dystocia in Sheep, life-saving surgical procedure

Article Info

Accepted: 15 September 2018 Available Online: 10 October 2018
Cesarean section is a life-saving surgical procedure usually undertaken in sheep and goats that fail to deliver vaginally (dystocia). A local non descript breed of sheep was presented to veterinary teaching clinical complex with difficulty in parturition. Fetal examination revealed dead fetus with no fetal reflex. Cesarean section was undertaken in ewe and the dead fetus was successfully taken out followed by post operative care. The case was followed up for 2 weeks after treatment and the ewe was bright and alert and responded well to the treatment.

\section{Introduction}

In small ruminants, the incidence of dystocia is low compared to large ruminants $(<5 \%)$ (Bhattacharyya et al., 2015; Brounts et al., 2004; Engum and Lyngset, 1970; Franklin, 1986). Dystocia usually occurs when the first or second stages of parturition are delayed or when the first stage fail to progress to the next stage within 30 minutes (Brounts et al., 2004; Engum and Lyngset, 1970; Franklin, 1986; Fubini and Ducharme, 2004; Ghosh et al.,
1992). It is a main factor in the peri-natal death of dams and newborns due to damage of the birth canal and excessive use of traction forces (Rook et al., 1990; Ghosh et al., 1992; Brounts et al., 2004; Scott, 2005). Generally dystocia may be of fetal or maternal origin (Noakes et al., 2009). Fetal dystocia occurred mainly due to oversize, mal-disposition, and monsters (Engum and Lyngset, 1970; Rahim and Arthur, 1982; Majeed and Taha, 1989a; Noakes et al., 2009). Maternal dystocia were mainly due to a deficient dilatation of the 
cervical canal (ringwomb), narrow pelvis and uterine inertia (Franklin, 1986; Majeed and Taha, 1989b; Thomas, 1992; Noakes et al., 2009).

\section{History}

A local non-descript breed of sheep weighing $30 \mathrm{~kg}$ was presented to veterinary teaching clinical complex FVSc \& AH, R.S Pura SKUAST Jammu with a history of difficulty in giving birth (Fig. 1). The process of parturition commenced in the night before presentation to the hospital.

\section{Physical examination}

Physical examination revealed tachycardia, mild dehydration and pale mucous membrane. The ewe was weak and on recumbent position. There was rupture of the fetal membrane and protrusion of a fetus head out from the vulva region with mild discharge from vagina. Fetal examination revealed that the fetus was already dead as there was no fetal reflex.

The fetal presentation was found as normal with anterior presentation and dorso-sacral position, but posture was abnormal with carpal joint flexed at right forelimb. Based on the per-vaginal examination, the condition was diagnosed as fetal dystocia due to unilateral carpal flexion posture.

\section{Treatment and management procedure}

The therapeutic plan for this case was to remove the dead fetus via traction method after subsidence of unilateral carpal flexion. The traction was applied after proper lubrication of reproductive canal using liquid paraffin. Caudal epidural anesthesia was performed between first and second intercoccygeal space using $3 \mathrm{~mL}$ Lignocaine hydrochloride $2 \%$ before the procedure to prevent straining.

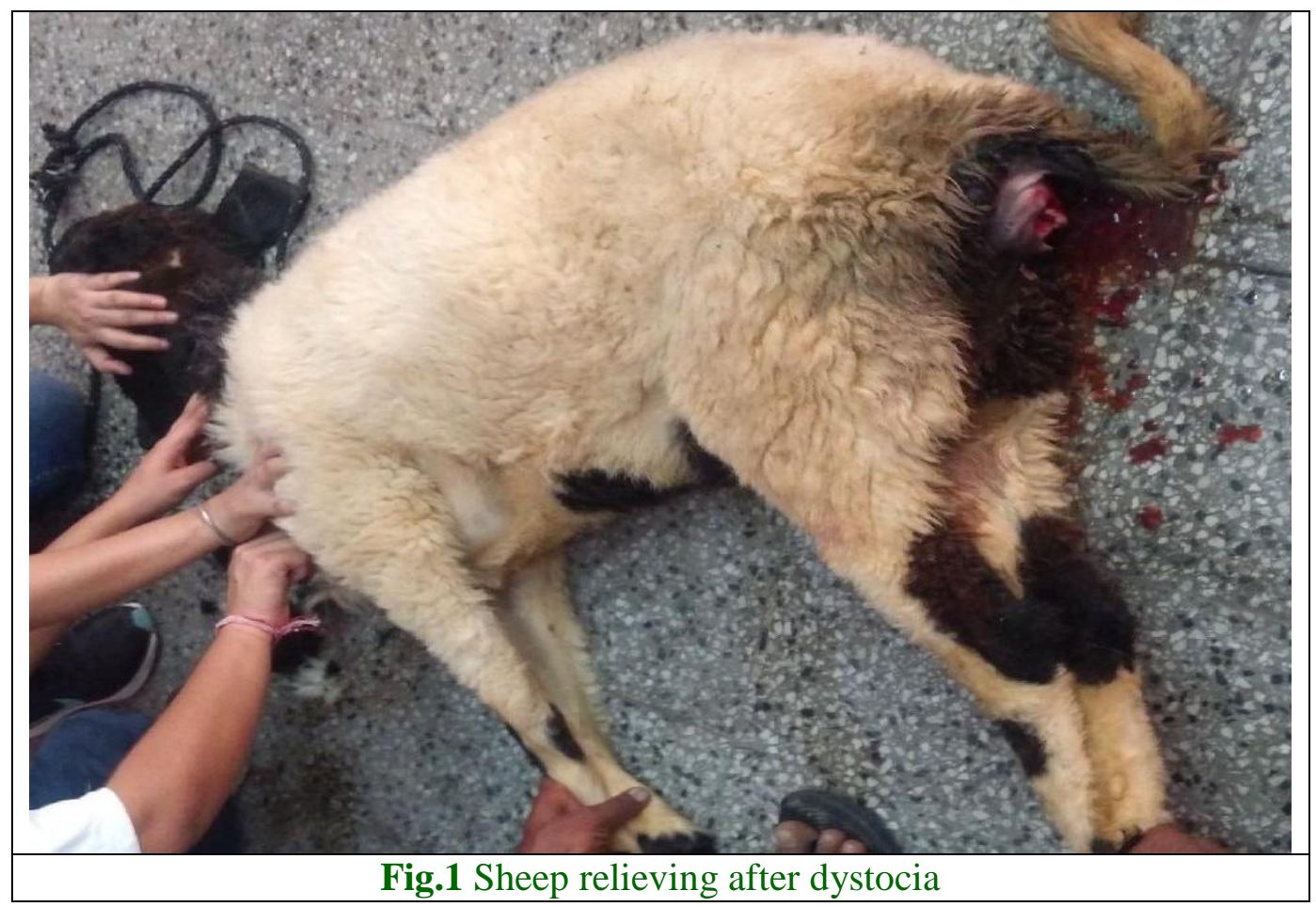




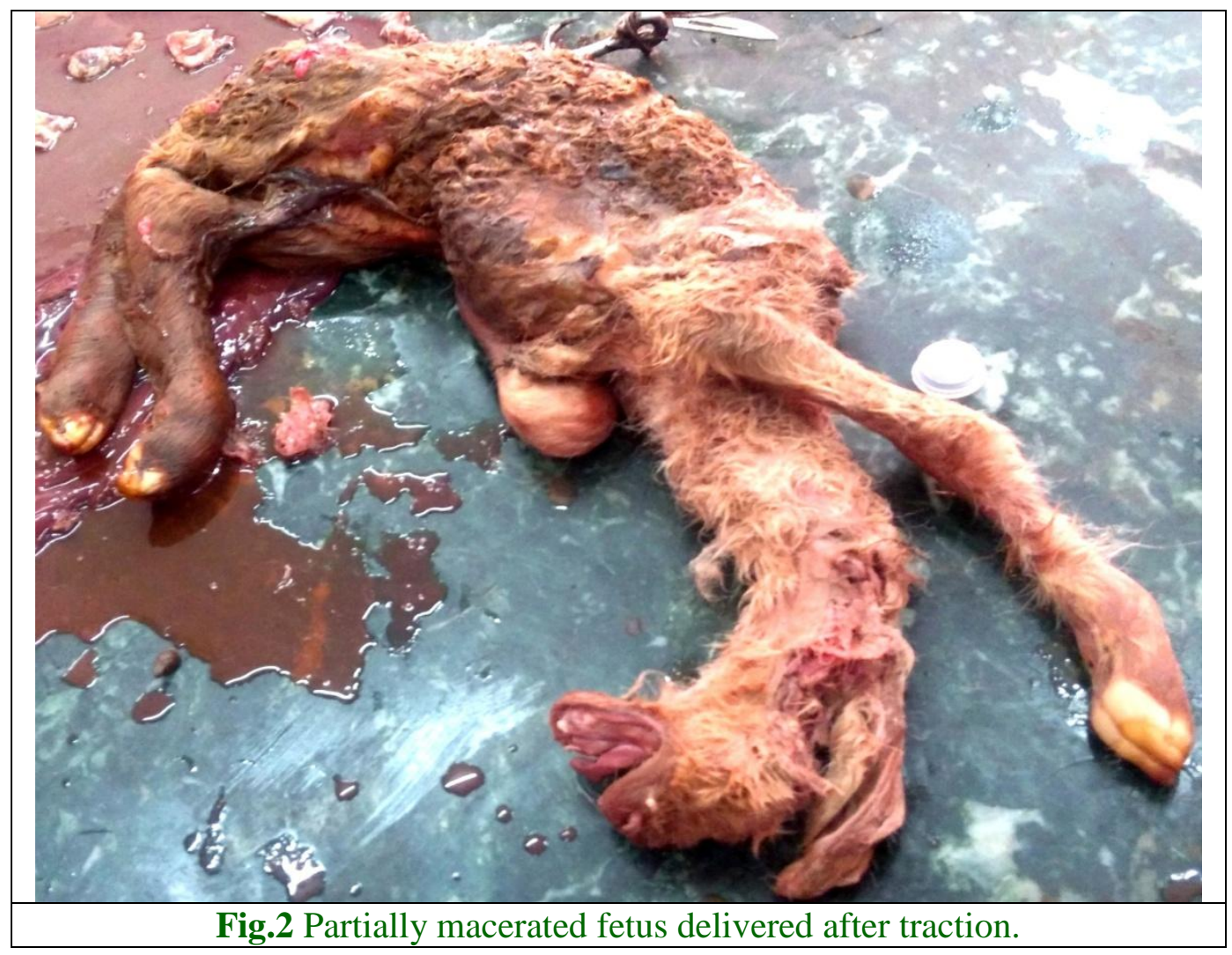

But the ewe was unable to deliver the foetus even after applying the traction due to lack of enough space. Episiotomy was done by making incision on the vulvar wall. Due to which enough space was created which facilitated easy delivery of fetus after proper traction.

One dead macerated fetus was delivered (Fig. 2). Intrauterine flush was performed using $150 \mathrm{~mL}$ of $0.85 \% \mathrm{NaCl}$ solution, and followed by administration of 2 furea bolus. This was followed by administration of antibiotic (5ml of enrocin), analgesic ( $2 \mathrm{ml}$ of melonex), corticosteroid ( $2 \mathrm{ml}$ of Dexona), supplementary therapy of tribvet @ $5 \mathrm{ml}$ and uterine cleanser utrifit @10ml orally.

The above treatment was repeated for 3 days. Finally, the incision site was sutured using 30 silk with simple interrupted suture pattern. Iodine paste was applied at the suture site as antiseptic and fly repellent.

\section{Progression}

The case was followed up for 2 weeks after treatment where the ewe responded well to the treatment.

The ewe was bright and alert. The suture site was clean and intact, and suture removal was performed.

\section{References}

Bhattacharyya, H.K., Fazili, M.R., Bhat, F.A., Buchoo, B.A. (2015). Prevalence and dystocia of sheep and goats: A study of 70 cases (2004-2011). J. Adv. Vet. Res. $5,14-20$.

Brounts, S.H., Hawkins, J.F., Baird, A.N., Glickman, L.T., 2004. Outcome and subsequent fertility of sheep and goats undergoing cesarean section because of dystocia: 110 cases (1981-2001). J. Am. Vet. Med. Assoc. 224, 275-279. 
Engum, J., Lyngset, O., 1970. Gynaecology and obstetrics in the goat. Iowa State Univ. Vet. 120, 120-124.

Franklin, J.S., 1986. Dystocia and Obstetrics in Goats. In: D.A. Morrow (Editor), Current Therapy in Theriogenology, 2nd ed., W.B. Sannders, Philadelphia.

Fubini, S.L., Ducharme, N.G. (2004). Farm animal surgery. Missouri, Saunders.

Ghosh, A., Yeasmina, F., Alam, M.G.S., 1992. Studies of ringwomb in Black Bengal goats. Theriogenology 37, 527532.

Majeed, A.F., Taha, M.B. 1989a. Dystocia in local goats in Iraq. Small Rumin Res 2, 375-381.

Majeed, A.F., Taha, M.B., 1989b. Preliminary study on treatment of ringwomb in Iraqi goats. 18, 199-203.

Noakes, D.E., Parkinson, T.J., England, G.C.W. (2009). Noakes's' veterinary reproduction and obstetrics. London, Saunders.

Noakes, D.E., Parkinson, T.J., England, G.C.W., 2009. Arthuts' Veterinary reproduction and obstetrics, 9th edition, DE Noakes, TJ Parkinson, GCW
England (eds), Saunders, Edinburg, London.

Purohit, G.N. (2006). Dystocia in the sheep and goat. A review. Indian J. Sm. Rum. 12(1), 1-12.

Rahim, A.T., Arthur, G.H., 1982. Obstetrical conditions in goats. Cornell Veterinarian 72, 279-284.

Rook, J.S., Scholman, G., Wing-Proctor, S., Shea, M., 1990. Diagnosis and control of neonatal losses in sheep. Vet. Clin. North. Am. Food. Anim. Pract. 6, 531562.

Scott, P.R. Naqvi, S.M., Pandey, G.K., Gautam, K.K., Joshi, A., Geethalakshmi, V., Mittal, J.P., 2005. The management and welfare of some common ovine obstetrical problems in the United Kingdom. Vet. J. 170, 33-40. Review.

Sharma, A., Kumar, P., Singh, M., Vasishta, N. (2014). Retrospective analysis of dystocia in small ruminants. Intas Polivet. 15, 287-289.

Thomas, J.O., 1992. Survey of the causes of dystocia in sheep. Vet. Rec. 127, 574575.

\section{How to cite this article:}

Pandey, A.K., Mir Mudasir, Jaan Mohammad Wani, Sharad Kumar and Sudhir Kumar. 2018. Management of Dystocia in Sheep - A Case Report. Int.J.Curr.Microbiol.App.Sci. 7(10): 18001803. doi: https://doi.org/10.20546/ijcmas.2018.710.205 